\title{
Direitos e responsabilidade pelo seu custeio: proposta para se analisar os custos da inserção no âmbito de uma sociedade democrática solidária
}

\author{
Rights and responsibility for their cost: proposal to analyze the costs of insertion \\ within a democratic society of solidarity
}

\author{
Liliane Gonçalves Matos* \\ Natércia Sampaio Siqueira**
}

\section{Resumo}

O objetivo deste trabalho é analisar a decisão proferida pelo Supremo Tribunal Federal em sede de ADIN n 5357/DF, quando se decidiu pela obrigatoriedade de as instituições privadas de ensino promoverem medidas necessárias para a adaptação de estudantes com deficiência de ensino básico sem que haja o devido repasse de custos aos pais daqueles que usufruírem delas, sob o enfoque da atribuição de responsabilidade social no custeio de direitos. Para tanto, fez-se uso de uma pesquisa descritiva-analítica, de caráter bibliográfico, sobre: a) a equidade referente às democracias, para o que a educação se mostra instrumento imprescindível para assegurar justas oportunidades de preenchimento dos cargos e funções sociais; e b) o modelo constitucional para o custeio dos direitos. Como resultado, verificou-se que a proibição de discriminar os estudantes que farão jus às medidas requisitadas tenderá a promover o incremento dos custos de transação, que serão absolvidos por todos os consumidores. Concluiu-se que as medidas de inclusão são políticas públicas, de maneira que o seu custeio deve se dar pelo modelo constitucional de atribuição de responsabilidade pelo financiamento de direitos.

Palavras-chave: Inclusão de pessoas com deficiências. Educação. Custeio de políticas públicas.

\section{Abstract}

The object this article is to analyze the decision handed down by the Federal Supreme Court in ADIN $n^{\circ}$ 5357/DF where it decided that private educational institutions should promote the necessary measures for the adaptation of students with disabilities to basic education without the necessary transfer of the parents of those who enjoy them. In order to do so, a descriptive-analytical and bibliographic research was made that the theories of justice, passing through Rawls, Amartya Sen and Dworkin, ending in the limits of the solidarity. As a result, it has been found that the prohibition against discriminating students who will qualify for the requisite measures will lead to an increase in transaction costs that will be cleared by all consumers by making or increasing tuition increases unfeasible. It was concluded that inclusion measures are of a public policy nature, so if families can not afford to pay, it is the State that should be called upon to pay for them and not entrust such responsibility to the private sector.

Keywords: Inclusion of people with disabilities. Education. Costing of public policies.

\section{Introdução}

O objetivo deste trabalho é analisar a decisão proferida pelo Supremo Tribunal Federal em sede de ADIN, em que se decidiu pela obrigatoriedade de as instituições privadas de ensino promoverem medidas necessárias para a adaptação de estudantes com deficiência no ensino básico, sem que haja o devido repasse

Mestra em Direito Constitucional com ênfase Direito Privado pela Universidade de Fortaleza - UNIFOR. Especialista em Direito e Processo Empresarial pela Unifor. Especialista em Direito e Processo Tributário pela Unifor. Fortaleza - CE - Brasil. E-mail: liliane.mat@hotmail.com.

** Doutora em Direito Constitucional pela Universidade de Fortaleza - UNIFOR. Mestra em Direito Tributário pela Universidade Federal de Minas Gerais - UFMG. Professora Titular do Programa de Pós-Graduação em Direito da Universidade de Fortaleza. Procuradora Fiscal do Município de Fortaleza. Fortaleza - CE- Brasil. E-mail: naterciasiqueira@yahoo.com.br. 
de custos aos respectivos pais, o que se propõe a fazer sob o enfoque da atribuição de responsabilidade social no custeio de direitos. $\mathrm{O}$ artigo, mais do que abordar a relação entre equidade, justa oportunidade e educação, trabalha os fundamentos à integração e à inserção das pessoas com deficiência na teoria da justiça que se considera adequada à democracia, ao tempo em que trata do modelo constitucional que seria o adequado para o financiamento de direitos e das funções públicas.

Para tanto, o trabalho divide-se em quatro tópicos. O primeiro trata do acesso à educação como direito e dever fundamental e da condição das pessoas com deficiência, ocasião em que se traz a Lei de Diretrizes Bases e Educação Nacional e a Convenção Internacional de Nova lorque, que trata, especificamente, das pessoas com deficiência.

No segundo tópico analisa-se a relação entre justa oportunidade e a equidade, compreendida como nota elementar da democracia. Por ocasião, adota-se por marco teórico o liberalismo de Rawls e Dworkin, uma vez que se compartilha da teoria de que a axiologia liberal é anterior, informante e condicionante das instituições sociais basilares de uma democracia, tais como o direito, a economia, a política. A ambiência de que se cuida é a democrática: as várias experiências particulares da democracia guardam em comum um eixo fundante de razões que deve ser explorado, de maneira que as análises não singrem ora pelo positivismo travestido na vontade do constituinte originário, ora pelo subjetivismo resguardado nas dobras do sopesamento.

Levantado o fundamento do direito à educação e à inserção, inicia-se a análise da decisão proferida no julgamento da ADIN n 5357, proposta pela Confenen. Posteriormente, trabalha-se o modelo constitucional de custeio dos direitos e das funções públicas, quando se traça os conceitos de: Estado patrimonial, tributário e fiscal, razões de tributação e políticas de meios e de fins. Como resultado, chega-se à conclusão de que o que excede a possibilidade de se impor condicionamentos à iniciativa privada, mas que deve ser assegurado a título de direitos reconhecidos normativamente, deve ser fomentado por políticas estatais custeadas por uma tributação com causa na capacidade contributiva. Mais ainda: que os princípios constitucionais tributários não se restringem aos impostos e tributos de caráter contributivo; antes, informam um modelo constitucional de atribuição de responsabilidade no custeio de direitos e funções públicas.

Diante do propósito de, a partir da teoria da justiça e de textos normativos, se delimitar o modelo de custeio de direitos, adota-se a metodologia baseada em um estudo descritivo-analítico, mediante pesquisa de natureza qualitativa e do tipo bibliográfica. Compreende-se, no presente trabalho, que o problema ora tratado o deve ser pela perspectiva normativa, a prescindir de análises econômicas relativas às consequências dos possíveis modelos a serem adotados. O custeio de direitos possui uma metodologia traçada constitucionalmente, que deve ser pinçada, exposta e trazida ao debate no que tange à distribuição dos custos de direitos e políticas públicas.

\section{Acesso à educação e a deficiência}

A Constituição Federal do Brasil de 1988 dispõe sobre direitos e garantias fundamentais referentes ao indivíduo. Entre esses, no capítulo II, a educação é classificada como sendo um direito social. ${ }^{1}$ Mais adiante, a Constituição volta a tratar do tema no capítulo III, quando, ao imputar sua obrigatoriedade, a define como direito de todos e dever do Estado e da família, devendo ser promovida e incentivada com a colaboração da sociedade, visando ao pleno desenvolvimento da pessoa, seu preparo para o exercício da cidadania e sua qualificação para o trabalho. ${ }^{2}$

Assim, a CF determina que a educação é mais do que um direito, é um dever intrínseco da família e do Estado, e que deve ser promovida e incentivada por toda a sociedade. Isto porque a atribuição de direitos implica, consequentemente, a delimitação de responsabilidades pela sua implementação, que não é gratuita:

Art. $6^{\circ}$ da Constituição Federal do Brasil.

Art. 205, idem. 
Nevertheless, rights and responsibilities can hardly be separated; they are correlative. The mutual dependence of rights and responsibilities, their essential inextricability, makes it implausible to say that responsibilities are being 'ignored' because rights have 'gone too far'[...]

Ordinary contract law prohibits American courts from enforcing irresponsible debts, such as those contracts among gamblers. Such interdictions are natural, for contract law as a whole system for enforcing social responsibilities. The right of a promise for breach of promise is the classical illustration of the thesis that rights and duties are correlative. And the patter is general. Is Smith has a right to his property, then Jones has a duty not to trespass upon it. If Jones has a right to a percentage of the proceeds from his bestseller, the publisher has a duty to send him what he is due. To protect the rights of Smith the nonsmoker, the government must increase the responsibilities of Jones the smoker. If Jone's freedom of religion is constitutionally protect, public officials have toward him a duty of toleration. If Smith has a right to be free from racial discrimination in employment, employers have a duty to ignore the color of Smith's skin. If Jones has a right in a criminal trial to exclude evidence gathered illegally against him, the police have a duty to get a valid warrant before they search his house. If Smith has a right to sue a newspaper for libel, the newspaper has a duty to check its facts. ${ }^{3}$ (HOLMES; SUSTEIN, 1999, p. 140-144).

Assim sendo, a outra face da moeda de um direito é a responsabilidade pelo seu implemento. A Constituição, em relação à educação, a atribui ao Estado, à família e à sociedade, com o propósito de efetivamente assegurar o desenvolvimento da pessoa em todas as suas potencialidades e, principalmente, no âmbito do intelecto humano. O legislador não poupou esforços em atribuir a responsabilidade pela educação entre os diferentes sujeitos que integram a sociedade. "Em Platão, por exemplo, 'não é a ideia de direito à educação que prevalece; a educação é um dever: o Estado deve obrigar as crianças a instruíremse, porque pertencem à cidade mais do que aos pais'” (COMPERNOLLE, 1975, p. 99).

Na construção da cidadania e da personalidade individualizada do ser humano, a racionalidade é elemento de destaque e se desenvolve, preferencialmente, pelo acesso à educação, que trabalha a capacidade de apreender, compreender e elaborar, mesmo que, inicialmente, de forma empírica, o conhecimento. É na escola 4 que os indivíduos têm o seu primeiro contato com a coletividade, com o trabalho em grupo, com a diversidade, entre outros tantos benefícios. Enfim, o direito fundamental à educação "significa um recorte universalista próprio de uma cidadania ampliada e ansiosa por encontros e reencontros com uma democracia civil, social, política e cultural” (CURY, 2008, p. 294). Neste sentido, escreve Raposo (2005, p. 1):

A educação, enquanto dever do Estado e realidade social, não foge ao controle do Direito. Na verdade, é a própria Constituição Federal que a enuncia como direito de todos, dever do Estado e da família, com a tríplice função de garantir a realização plena do ser humano, inseri-lo no contexto do Estado Democrático e qualificá-lo para o mundo do trabalho. A um só tempo, a educação representa tanto mecanismo de desenvolvimento pessoal do indivíduo como da própria sociedade em que ele se insere.

Além de ser um direito social, a educação, como experiência fundamental à racionalidade, à sociabilidade e à cidadania, apresenta-se como pré-requisito para se usufruir dos direitos civis, políticos e sociais, o que

\footnotetext{
"No entanto, direitos e responsabilidades dificilmente podem ser separados; eles são correlativos. A dependência mútua de direitos e responsabilidades, sua inextricabilidade essencial, torna implausível dizer que as responsabilidades estão sendo "ignoradas" porque os direitos "foram longe demais" [...]. O direito contratual ordinário proíbe os tribunais americanos de aplicar dívidas irresponsáveis, como os contratos entre os jogadores. Tais interdições são naturais, para o direito contratual como um sistema completo para impor responsabilidades sociais. O direito de uma promessa por quebra de promessa é a ilustração clássica da tese de que direitos e deveres são correlativos. E o padrão é geral. Smith tem o direito de sua propriedade, então Jones tem o dever de não transgredi-lo. Se Jones tem direito a uma porcentagem dos lucros de seu best-seller, o editor tem o dever de lhe enviar o que lhe é devido. Para proteger os direitos de Smith, o não-fumante, o governo deve aumentar as responsabilidades de Jones, o fumante. Se a liberdade de religião de Jone é constitucionalmente protegida, os funcionários públicos têm em relação a ele um dever de tolerância. Se Smith tem o direito de ser livre de discriminação racial no emprego, os empregadores têm o dever de ignorar a cor da pele de Smith. Se Jones tem o direito, em um julgamento criminal, de excluir provas reunidas ilegalmente contra ele, a polícia tem o dever de obter um mandado válido antes de revistar sua casa. Se Smith tem o direito de processar um jornal por difamação, o jornal tem o dever de verificar seus fatos".

4 Segundo o Novo Dicionário da Língua Portuguesa, de Aurélio Buarque de Holanda Ferreira, escola é o estabelecimento público ou privado onde se ministra, sistematicamente, ensino coletivo.
} 
explica emergir como componente básico dos Direitos do Homem ${ }^{5}$ (OREALC/UNESCO, 2007). É de tal monta a sua importância, que todas as constituições brasileiras trouxeram normas específicas sobre a sua disciplina no território nacional, mesmo que algumas o tenham feito de forma superficial. Foi pela percepção de que só por "meio da educação os sujeitos podem se constituir senhores da sua vida e autores de sua história” (FREIRE, 2000, p. 51), que os olhos se voltaram para uma parte da sociedade por vezes esquecida, ignorada e até depreciada: as pessoas com deficiência.

O olhar sensível às necessidades das pessoas com deficiência, sejam de ordem física, seja mental, significou importante mudança na compreensão da humanidade sobre si. Para além de se reconhecer a igual dignidade que o "humano", nas suas múltiplas manifestações, reivindica, o esforço se direciona para a inserção, integração e igual respeito aos diferentes modelos de funcionamento humano. Portanto, ao invés de se investir em um modelo abstrato e asséptico de ser humano, passa-se a reconhecer o "humano" nas suas manifestações concretas e, por conseguinte, a se trabalhar a significação social das diferenças não como "ruins" ou "boas", mas como, simplesmente, predicados e condicionamentos pessoais que demandam igual respeito e consideração. Tal meta torna-se objeto de políticas públicas que, ao abraçá-la, têm elaborado uma nova agenda de cidadania sob o investimento na identidade, com enfoque especial na educação. Sobre o assunto, fala Cury $(2005$, p. 12) que:

Políticas inclusivas supõem uma adequação efetiva ao conceito avançado de cidadania coberto pelo ordenamento jurídico do país. É ainda dentro dos espaços nacionais, espectro privilegiado da cidadania, que se constroem políticas duradouras em vista de uma democratização de bens sociais, aí compreendida a educação escolar. Afinal, cidadania e nação são construções históricas, mas não são objetos de uma relação imanente e ontológica.

Na galgar pela inclusão, foi promulgada, pelo Decreto $n^{\circ} 6.949 / 2009,{ }^{6}$ a Convenção Internacional sobre os Direitos das Pessoas com Deficiência, ${ }^{7}$ dotada do propósito de promover, proteger e assegurar o exercício pleno e equitativo dos direitos humanos e liberdades fundamentais por todas as pessoas com deficiência, mediante o respeito pela sua inerente dignidade (art. $1^{\circ}$ ). Entretanto, apesar da guinada referencial pela perspectiva cidadã inclusiva, vê-se, não raro, a recusa de alguns estabelecimentos de ensino em aceitar alunos pelos mais diferentes motivos; entre eles, a deficiência física, que exigiria do ambiente escolar condições específicas de adaptabilidade e acolhimento.

Mas por ser a educação reconhecida como direito de todos, tanto na Constituição como na Lei de Diretrizes Bases e Educação Nacional, ${ }^{8}$ argúi-se que a educação básica seria obrigatória, de maneira que não se poderia vedar o acesso de alunos com condições especiais. Todas as instituições educacionais teriam de acolher os estudantes, sem qualquer tipo de discriminação.

A incumbência legal de recepcionar os alunos não se aplicaria apenas às instituições públicas de ensino, pois o governo tem o dever de amparar e adaptar sem ônus algum aqueles a quem o serviço público é dirigido. Ela se direcionaria também às particulares, que se veriam diante da proibição de escalonar valores para cobrir os gastos oriundos da adaptação do espaço. É isto, precisamente, o que se pretende abordar no presente artigo, a "eficácia horizontal" dos direitos sociais. Eis o grande problema que se apresenta à educação inclusiva: a atribuição de responsabilidade pelo custeio "horizontal" de direitos.

ONU, organismo internacional, em 10 de dezembro de 1948, proclama a Declaração Universal dos Direitos Humanos como expressão "do reconhecimento da dignidade inerente a todos os membros da família humana e de seus direitos iguais e inalienáveis". Entre esses direitos tem-se que a instrução será gratuita, pelo menos nos graus elementar e fundamental. Quando a instrução elementar será obrigatória e a técnico-profissional acessível a todos, bem como a instrução superior, esta baseada no mérito; a instrução será orientada no sentido do pleno desenvolvimento da personalidade humana e do fortalecimento do respeito pelos direitos do homem e pelas liberdades fundamentais. A instrução promoverá a compreensão, a tolerância e a amizade entre todas as nações e grupos raciais ou religiosos, e coadjuvará as atividades das Nações Unidas em prol da manutenção da paz. (BRASIL, 1997, art. 26, p. 134).

6 Com status equivalente ao de emenda constitucional, reforçando o compromisso internacional da República com a defesa dos direitos humanos e compondo o bloco de constitucionalidade que funda o ordenamento jurídico pátrio.

A Convenção sobre os Direitos das Pessoas com Deficiência foi assinada em Nova lorque, Estados Unidos da América, em 30 de março de 2007 (BRASIL, 2015).

$8 \quad$ Lei $n^{\circ} 9.394 / 96$. 


\section{Justa oportunidade, capacidade, inclusão e identidade}

A um primeiro momento, importa considerar que a equidade está intrinsecamente relacionada com a justa oportunidade de preenchimento de cargos e funções sociais de responsabilidade. A equidade fundamenta axiologicamente a justa oportunidade que a realiza.

Para se compreender o acima afirmado, releva trazer a compreensão de John Rawls (2000) de que a sociedade democrática é aquela que se constitui por uma relação de cooperação entre pessoas livres e iguais. Por conseguinte, ela se indispõe, ontologicamente, a uma sociedade de hierarquias. Mas, para que se assegure essa sociedade equitativa, segundo Rawls (1999), é necessário: a) que a sociedade se estruture sem comprometimento com uma teoria específica do bem; b) que os processos de tomada de decisão, sejam políticas, sejam econômicas, não beneficiem ou prejudiquem, arbitrariamente, determinada concepção do bem.

Mas para que esta última exigência seja atendida, faz-se necessário que se oportunizem justas oportunidades para o preenchimento de cargos e funções de responsabilidades, de maneira que se possa participar equanimemente das deliberações, sejam de Estado, sejam de mercado, que impactam as preferências pessoais e sociais.

No presente ponto, importa ressaltar que, embora não se possa impedir que as decisões de Estado e de mercado interfiram nas escolhas de vida, elas se revelam equânime não quando são neutras quanto à produção de seus resultados (RAWLS, 1999, p. 459-460), mas quando decorrem de um processo equitativo de deliberação e decisão, para o que a justa oportunidade de participação é condição necessária. Isto significa que ainda que se esteja a trabalhar com a teoria de Rawls, não se pode olvidar do propósito de se "capacitar" a pessoa para concorrer, mediante justa oportunidade, no preenchimento de cargos e funções abertos a todos. Para tanto, já na Theory of Justice, consta o entendimento de que a educação se revela imprescindível (RAWLS, 1971, p. 73):

The liberal interpretation of the two principles seeks, then, to mitigate the influence of social contingences
and natural fortune on distributive shares. To accomplish this end it is necessary to impose further
basic structural conditions on the social system. Free market arrangements must be set within a
framework of political and legal institutions which regulates the overall trends of economic events
and preserves the social conditions necessary for fair equality of opportunity. The elements of this
framework are familiar enough, though it may be worthwile to recall the importance of preventing
excessive accumulations of property and wealth and of maintaining equal opportunities of education
for all. Chances to acquire cultural knowledge and skills should not depend upon one's class position,
and so the school system, whether public or private, should be designed to even out class barriers.

Não se negam os paradoxos e os limites recíprocos entre as abordagens dos recursos e da capacidade, mas ambas também se interceptam, em especial referente à educação, tanto porque a educação habilita tecnicamente a pessoa à profissão, ao engajamento social e político como porque atua como poderoso instrumento de formação cidadã numa axiologia do igual respeito e consideração, de equilíbrio de poderes sociais, de requalificação e reconhecimento.

Em tempos nos quais os conflitos não se limitam mais à dicotomia entre o proletariado e os donos dos meios de produção, mas antes abraçam a demanda da identidade (INNERARITY, 2016, p. 67), a educação, como fator de formação, requalificação e reconhecimento, torna-se fundamental para a pacificação social. Ela é o instrumento imprescindível para que se assegurem justas oportunidades de preenchimento de cargos e funções. Por conseguinte, de participação nas tomadas de decisão, ou seja, de construção de uma efetiva sociedade equitativa entre iguais.

\footnotetext{
A interpretação liberal dos dois princípios busca, então, mitigar a influência das contingências sociais e da fortuna natural nas ações distributivas. Para tanto, é necessário impor condições estruturais básicas ao sistema social. Os acordos de livre mercado devem ser estabelecidos dentro de uma estrutura de instituições políticas e jurídicas que regulam as tendências gerais dos eventos econômicos e preservam as condições sociais necessárias para a igualdade e justa de oportunidades. Os elementos dessa estrutura são bastante familiares, embora possa valer a pena recordar a importância de evitar acumulações excessivas de propriedade e riqueza e de manter oportunidades iguais de educação para todos. As chances de adquirir conhecimentos e habilidades culturais não devem depender da posição de uma classe e, portanto, o sistema escolar, seja ele público ou privado, deve ser projetado para nivelar barreiras de classe.
} 
Nesse contexto, deve-se apreender a educação como dever social e direito fundamental, que deve ser assegurado indistintamente a todos os indivíduos de modo a possibilitar a igualdade de recursos, sem que haja rejeição a um ou outro grupo social. É imprescindível que o Estado trate os cidadãos com igual consideração, sem usurpar ou dificultar o acesso a qualquer meio de vida escolhido. Além disso, que assegure justas oportunidades de preenchimento de cargos e funções sociais de responsabilidade, seja no mercado econômico, seja na política. Isto porque, repita-se uma vez a mais, a justa oportunidade, a qualificar os atores políticos e econômicos, obsta mecanismos viciados de estímulo ou desestímulo de determinados modelos de vida e concepções do bem, ao tempo em que inspira o sentimento da igual importância e participação. Daí a relevância que a educação apresenta, em especial, às pessoas com deficiência, física ou mental. Mais do que superar os efeitos decorrentes das deficiência, insistindo-se em um modelo estereotipado e generalizante do normal, trabalha-se o reconhecimento da igual importância entre os diferentes. ${ }^{10}$ Redistribuir status e configurações sociais, políticas e econômicas, por uma dinâmica equitativa é o grande desafio para a realização de uma verdadeira democracia.

\title{
4 Análise da decisão do Supremo
}

A educação, de outra sorte, para que se assegure uma real inclusão, deve ter redimensionado seu papel e suas expertises. É o que escreve Mantoan (2006, p. 5455):

\begin{abstract}
No caso de uma formação inicial e continuada direcionada à inclusão escolar, estamos diante de uma proposta de trabalho que não se encaixa em uma especialização, extensão ou atualização de conhecimentos pedagógicos. Ensinar, na perspectiva inclusiva, significa ressignificar o papel do professor, da escola, da educação e de práticas pedagógicas que são usuais no contexto excludente do nosso ensino, em todos os seus níveis. A inclusão escolar não cabe em um paradigma tradicional de educação e, assim sendo, uma preparação do professor nessa direção requer um design diferente das propostas de profissionalização existentes e de uma formação em serviço que também muda, porque as escolas não serão mais as mesmas, se abraçarem esse novo projeto educacional. ${ }^{11}$
\end{abstract}

O Estado e a sociedade passam a abraçar o projeto de que a educação se direciona à individualidade do aluno, com o propósito de dirimir as reais dificuldades apresentadas por cada um. Essa individualização ajuda a formatar o perfil de identificação da criança e o distingue no mundo. A educação também passa a abraçar o estilo afetivo freudiano (ILLOUZ, 2011, p. 15-16), caracterizado pela autenticidade na vida e afetos cotidianos e, consequentemente, pela individualidade, isto é, cada qual é único e se lhe deve assegurar o desenvolvimento autêntico. Nesse diapasão, um dos principais deveres da educação passa a ser instigar nos alunos a reflexão e a criticidade, de maneira que possam pensar por si próprios, e não apenas serem depósitos e propagadores do discurso de seus professores. Mais do que um arquivo de dados, deve-se promover o desenvolvimento do aluno nas suas capacidades para se inserir e participar de uma estrutura social caracterizada pela cooperação entre iguais. Mas referido redimensionamento tem custos, o que leva ao questionamento pela sua responsabilidade.

Sobre o referido assunto, em 09 de junho de 2016, o Supremo Tribunal Federal se manifestou no julgamento da ADIN n 5357, formulada pela Confederação Nacional dos Estabelecimentos de Ensino Confenen, contra a Lei 13.146/2015 de origem do Distrito Federal. A Confenen alegou violação aos arts. $5^{\circ}$, caput, incisos XXII, XXIII, LIV, 170, incisos II e III, 205, 206, caput, incisos II e III, 208, caput, inciso III, 209, 227, caput, $\S 1^{\circ}$, inciso II, todos da Constituição da República, em razão de a legislação ter instituído

10 Lei 13.146/2015: "Art. 27. A educação constitui direito da pessoa com deficiência, assegurado sistema educacional inclusivo em todos os níveis e aprendizado ao longo de toda a vida, de forma a alcançar o máximo desenvolvimento possível de seus talentos e habilidades físicas, sensoriais, intelectuais e sociais, segundo suas características, interesses e necessidades de aprendizagem".

11 No mesmo sentido, Goes (s.d., p. 4): Incluir alunos especiais na escola regular, não é somente transferir os mesmos de uma escola especial para a regular, ou seja, além de mudanças na estrutura dos edifícios escolares, tem que haver preparação para os professores, para que deem a assistência necessária a esses alunos, essas mudanças são necessárias, pois não é possível falar em inclusão sem que haja ajustes de cada unidade escolar e adaptações curriculares. A inclusão é um processo que contribui para a construção de um novo tipo de sociedade através de transformações, pequenas e grandes, nos ambientes físicos (espaços internos e externos, equipamentos, aparelhos e utensílios, mobiliários e meios de transportes) e na mentalidade de todas as pessoas, portanto também do próprio sujeito com necessidades especiais. 
a obrigatoriedade de as escolas privadas oferecerem atendimento educacional adequado e inclusivo às pessoas com deficiência. A autora alegou que tais medidas seriam de alto custo para as escolas privadas, 0 que violaria os dispositivos constitucionais supramencionados, pois levaria ao encerramento das atividades de muitas delas. Mas o STF não se sensibilizou, conforme consta da Ementa do acórdão:

EMENTA: AÇÃO DIRETA DE INCONSTITUCIONALIDADE. MEDIDA CAUTELAR. LEI 13.146/2015. ESTATUTO DA PESSOA COM DEFICIÊNCIA. ENSINO INCLUSIVO. CONVENÇÃO INTERNACIONAL SOBRE OS DIREITOS DA PESSOA COM DEFICIÊNCIA. INDEFERIMENTO DAMEDIDA CAUTELAR. CONSTITUCIONALIDADE DA LEI 13.146/2015 (arts. 28, § $1^{\circ}$ e 30, caput, da Lei $n^{\circ} 13.146 / 2015$ ). 1. A Convenção Internacional sobre os Direitos da Pessoa com Deficiência concretiza o princípio da igualdade como fundamento de uma sociedade democrática que respeita a dignidade humana. 2 . À luz da Convenção e, por consequência, da própria Constituição da República, o ensino inclusivo em todos os níveis de educação não é realidade estranha ao ordenamento jurídico pátrio, mas sim imperativo que se põe mediante regra explícita. 3. Nessa toada, a Constituição da República prevê em diversos dispositivos a proteção da pessoa com deficiência, conforme se verifica nos artigos $7^{\circ}$, XXXI, 23, II, 24, XIV, 37, VIII, 40, § $4^{\circ}, \mathrm{I}, 201, \S 1^{\circ}, 203$, IV e V, 208, III, 227, § $1^{\circ}$, II, e $\S 2^{\circ}$, e 244. 4. Pluralidade e igualdade são duas faces da mesma moeda. O respeito à pluralidade não prescinde do respeito ao princípio da igualdade. E na atual quadra histórica, uma leitura focada tão somente em seu aspecto formal não satisfaz a completude que exige o princípio. Assim, a igualdade não se esgota com a previsão normativa de acesso igualitário a bens jurídicos, mas engloba também a previsão normativa de medidas que efetivamente possibilitem tal acesso e sua efetivação concreta. 5. O enclausuramento em face do diferente furta o colorido da vivência cotidiana, privando-nos da estupefação diante do que se coloca como novo, como diferente. 6 . É somente com o convívio com a diferença e com o seu necessário acolhimento que pode haver a construção de uma sociedade livre, justa e solidária, em que o bem de todos seja promovido sem preconceitos de origem, raça, sexo, cor, idade e quaisquer outras formas de discriminação (Art. $3^{\circ}$, I e IV, CRFB). 7. A Lei n 13.146/2015 indica assumir o compromisso ético de acolhimento e pluralidade democrática adotados pela Constituição ao exigir que não apenas as escolas públicas, mas também as particulares deverão pautar sua atuação educacional a partir de todas as facetas e potencialidades que o direito fundamental à educação possui e que são densificadas em seu Capítulo IV. 8. Medida cautelar indeferida. 9. Conversão do julgamento do referendo do indeferimento da cautelar, por unanimidade, em julgamento definitivo de mérito, julgando, por maioria e nos termos do Voto do Min. Relator Edson Fachin, improcedente a presente ação direta de inconstitucionalidade. (ADI 5357 MC-Ref, Relator(a): Min. EDSON FACHIN, Tribunal Pleno, julgado em 09/06/2016, PROCESSO ELETRÔNICO DJe-240 DIVULG 10-11-2016 PUBLIC 11-11-2016).

Do voto do Relator, Ministro Fachin, destaque-se o princípio da solidariedade social, informante do objeto da lei, quando se afirma que a resposta jurídica para a questão posta somente pode ser realizada com um olhar que não se negue a ver a responsabilidade pela alteridade compreendida como elemento estruturante da narrativa constitucional:

A atuação do Estado na inclusão das pessoas com deficiência, quer mediante o seu braço Executivo ou Legislativo, pressupõe a maturação do entendimento de que se trata de ação positiva em uma dupla via. [..] Pluralidade e igualdade são duas faces da mesma moeda. O respeito à pluralidade não prescinde do respeito ao princípio da igualdade. E na atual quadra histórica, uma leitura focada tão somente em seu aspecto formal não satisfaz a completude que exige o princípio. Assim, a igualdade não se esgota com a previsão normativa de acesso igualitário a bens jurídicos, mas engloba também a previsão normativa de medidas que efetivamente possibilitem tal acesso e sua efetivação concreta. (BRASIL, ADIN n 5357, 2016, p. 13 - 14).

Mais adiante, ao correlacionar o direito à educação com a obrigatoriedade de as escolas privadas arcarem com os custos da inclusão (p. 17), o ministro dispara: "não obstante o serviço público de educação ser livre à iniciativa privada, ou seja, independentemente de concessão ou permissão, isso não significa que os agentes econômicos que o prestam o possam fazê-lo ilimitadamente ou sem responsabilidade". Portanto, à escola não é dado escolher, segregar, separar, pois é seu dever ensinar, incluir, conviver.

Para o relator, a Lei n 13.146/2015 "parece justamente assumir esse compromisso ético de acolhimento quando exige que não apenas as escolas públicas, mas também as particulares deverão pautar sua atuação 
educacional a partir de todas as facetas e potencialidades que o direito fundamental à educação possui e que são densificadas em seu Capítulo IV" (p. 19). Chega a afirmar que é apenas diante do convívio com a diferença e com o seu necessário acolhimento que pode haver a construção de uma sociedade livre, justa e solidária, em que o bem de todos seja promovido, sem preconceitos de origem, raça, sexo, cor, idade e quaisquer outras formas de discriminação (Art. $3^{\circ}$, I e IV, CRFB).

Ocorre que, por trás do discurso de cidadania, a Corte Máxima do país não se deteve na questão do custo. Apesar de a Constituição estabelecer que a educação é dever e direito básico, e que é de responsabilidade das famílias, do Estado e da sociedade, o custo deve ser levado em consideração, e não apenas pelo viés da reserva do possível. No momento, é interessante trazer à baila as considerações sobre o referido assunto feitas pelo Min. Marcos Aurélio (2016, p. 97 - 103) por ocasião do seu voto:

\begin{abstract}
O artigo 30, com força imperativa - como disse -, cogente, impõe adoção dessas providências, múltiplas providências, pelo setor privado. E fica este - tem-se mecanismos previstos a partir de formulários - impossibilitado, como se a vida econômica não fosse impiedosa - não se dá um passo sem se colocar a mão no bolso -, de proceder a qualquer cobrança. Será que essa Lei se coaduna com os ares constitucionais libertários que passamos a viver, após o regime de exceção, após 1988? Devemos, pelo menos, ter dúvidas. Mas, como disse o ministro Gilmar Mendes, há leis que são editadas - talvez para dar esperança vã à sociedade, impossível de frutificar - no campo do faz de conta. Daí ter me referido ao passado, quando o Brasil era pressionado para abolir a escravatura, veio a balha a denominada, à época, 'lei para inglês ver', porque as pressões maiores vinham da Inglaterra, credora, em diapasão maior do Brasil. Não se faz milagre no campo econômico-financeiro, e não pode o Estado cumprimentar com o chapéu alheio; não pode o Estado, se é que vivemos sob a proteção de uma Constituição democrática, compelir a iniciativa privada a fazer o que ele não faz, porque, quanto à educação, a obrigação principal é dele. Em se tratando de mercado, Presidente, a intervenção estatal há de ser minimalista. A educação é dever de todos, mas é dever precípuo do Estado. Existe a abertura, no artigo 209 da Constituição Federal, à iniciativa privada, que deve ser subsidiária. E, nesse mesmo artigo, existem aspectos a serem considerados - desde que o particular queira adentrar o campo educacional: cumprimento de normas gerais de educação nacional, autorização estatal para funcionamento do estabelecimento e avaliação de qualidade.
\end{abstract}

O fato é que a questão do custo deve também ser analisada pela indagação quanto à existência de um modelo constitucional de custeio dos gastos públicos e privados direcionados à efetivação de direitos, mesmo os qualificados de fundamentais. É o que abaixo se irá analisar.

\title{
5 Modelo constitucional para o custeio de direitos fundamentais ${ }^{12}$
}

De início, uma advertência: não se está a refutar a pertinência da cultura axiológica direcionada à justa oportunidade, que resulta mesmo de uma nova configuração social na qual os conflitos não mais se limitam à estrutura dicotômica entre o proletariado e o dono do capital. Antes, se diluem por novos e diferentes atores, que demandam o reconhecimento de predicados pessoais. Mas tal questão não obnubila outra: 0 modelo constitucional para se custear direitos.

Para se iniciar o referido assunto, é importante trazer o entendimento de que custear é uma das espécies de dever e responsabilidade, mas não todo o dever e responsabilidade. Isto significa, por um lado, que há deveres e responsabilidades que não o de custear, mas, por outro, que a atribuição de responsabilidade não implica, necessária e fatidicamente, a de custear, de maneira que da alteridade própria à responsabilidade, como contra face de um direito, não resulta, necessariamente, a liberdade de escolha quanto à atribuição e à estruturação da metodologia de custeio. Até porque, quanto ao dever de custear, a Constituição já traz o método adequado, que deve ser levado em consideração.

Para tanto e por óbvio, a análise da dogmática constitucional se faz necessária. Lembra-se, inicialmente, o disposto no art. 173 da CF/88, segundo o qual o Estado não deverá explorar atividade econômica, salvo

12 O presente tópico contém a sistematização sumarizada do que se entende pelo modelo constitucional de custeio do Estado constante do livro "Tributo, Mercado e Neutralidade no Estado Democrático de Direito", de autoria de Natercia Sampaio Siqueira. 
nos casos previstos na Constituição ou quando a exploração for necessária à segurança nacional e ao atendimento de relevantes interesses públicos, assim discriminados por lei. Concomitante, dispõe o art. 170 , caput, que a ordem econômica é fundada na iniciativa privada.

Desse contexto normativo decorre o reconhecimento da atividade econômica como própria da iniciativa privada. O Estado apenas deve exercê-la quando normativamente autorizado e em casos excepcionais. Noutras palavras: retira-se do Estado a possibilidade de explorar a atividade econômica, de maneira que o seu custeio passa a se concentrar, preferencialmente, no percebimento de riqueza derivada, isto é, aquela produzida pela iniciativa privada e que lhe é transferida; daí resulta que o Brasil classifica-se entre os Estados de natureza tributária, em contraposição aos patrimoniais:

Um estado deste tipo consubstanciou, desde logo, a primeira forma de estado (moderno) - o estado absoluto do iluminismo - que foi predominantemente um Estado não fiscal, uma vez que o seu suporte financeiro foram fundamentalmente, de um lado e em continuação das instituições medievais que o precederam, as receitas do seu patrimônio ou propriedade e, de outro, os rendimentos da actividade comercial e industrial por ele próprio assumida e desenvolvida em tributo ao ideário iluminista (NABAIS, 2004, p. 193)

Mas a Constituição não se limitou a atribuir ao Estado brasileiro a natureza de Estado tributário: ele é um Estado Fiscal, ou seja, é predominantemente custeado por impostos e por tributos de feição contributiva. Chega-se, precisamente, ao momento de ressaltar as diferentes razões jurídicas da tributação: remuneração e capacidade contributiva. De acordo com a primeira, os tributos apresentam caráter sinalagmático e decorrem do dever de custear ao Estado a atuação específica direcionada ao contribuinte ou o benefício particular que lhe foi gerado por uma atividade pública, ainda que inicialmente voltada à coletividade. A lógica desse custeio é a mesma da responsabilidade civil "objetiva" do Estado: se não é justo que uma pessoa seja particularmente prejudicada pela máquina pública, também não o é que ela seja, por si, especificamente beneficiada, ou que seja especialmente onerosa aos cofres estatais.

Já a outra razão é a capacidade contributiva: à medida que se tem riqueza apta à tributação, se é chamado ao custeio geral dos cofres públicos. Aqui, a tributação se despede do caráter sinalagmático e adquire perfil contributivo, pois se é chamado para "contribuir" com os gastos públicos. Ainda sobre o assunto, importa que se responda a questão de se a Constituição teria optado pela prevalência de algum desses modelos como forma prioritária de tributação. E a resposta é afirmativa, conforme o antecipado no parágrafo anterior. O Estado brasileiro é fiscal, o que significa que é custeado, prioritariamente, por impostos ou por tributos de função contributiva, com causa na capacidade contributiva.

Chega-se a essa resposta por vários motivos: a) de primeiro, pela maior atenção que a Constituição direciona ao regulamento de impostos e contribuições; b) de segundo, pelas diversas funções que a CF/88 atribuiu ao Estado: saúde, educação, assistência, forças armadas e segurança pública são exemplos. Ocorre que as referidas atuações, por serem prestadas a toda coletividade ou por serem, por determinação constitucional, filantrópicas, não se prestam a ser custeadas por uma tributação remuneratória, mas contributiva; c) de terceiro, pelo motivo de que uma tributação preferencialmente remuneratória estaria a "mercantilizar" o Estado; d) sem considerar que a remuneração não realiza a distribuição de riqueza, que possui finalidade em si: possibilitar justa oportunidade de preenchimento dos cargos e funções sociais (RAWLS, 2000, p. 144), que é inviabilizada pelo só fato da acumulação.

De outra sorte, para que a tributação de caráter contributivo seja eficaz, isto é, para que promova a distribuição de riqueza e não prejudique o núcleo essencial de direitos fundamentais, bem como demais princípios e interesses constitucionais, ela possui por causa jurídica a riqueza do contribuinte, pois uma tributação cuja distribuição do ônus fiscal ocorra sob o parâmetro da riqueza do particular tende a manter a neutralidade tributária no mercado econômico e a preservar a justa concorrência. Não por menos, é-se chamado a custear os gastos gerais do Estado se há riqueza e na sua medida (art. 145, caput c/c art. 150, II/CF), o que é aplicável, inclusive, ao se tratar de serviços públicos.

Também aqui a Constituição (art. 150, parágrafo terceiro) é expressa ao excluir a imunidade recíproca quando o Estado está a cobrar remuneração pela sua atuação, tanto porque ao assim agir estaria a 
explorar patrimônio, e estaria fora da álea do interesse público primário, como porque, se a prestação de serviço público também é livre ao particular, deve-se respeitar a justa concorrência e, consequentemente, a neutralidade tributária, o que já foi objeto de considerações pelo STF (RE 253472, informativo 597). Portanto, a exploração de qualquer atividade, quando livre ao particular, deve ser norteada pelo propósito de se criarem iguais regras para aqueles que se encontram em iguais situações, de maneira a se evitar regimes de apartheid fiscal que prejudicam a concorrência.

Dito de outra forma, a permissão para explorar uma atividade gera certos direitos, como o regime da justa concorrência, e a tributação que se dê pelo parâmetro da riqueza realiza a imposição isonômica de encargos fiscais, o que é imprescindível à concorrência. Pode-se, por conseguinte, argumentar que o modelo preferencial de custeio do Estado é o que se realiza por tributos de fato gerador não vinculado, cuja causa jurídica é a capacidade contributiva, tanto porque possibilita a distribuição de riqueza e o custeio de atividades filantrópicas, ou de fruição universal, como porque cria regime de tributação que se orienta pela igualdade e que não se fragmenta por nichos de privilégios fiscais a determinados agentes e atividades, o que prejudicaria a concorrência.

\subsection{Exercício das funções estatais}

Guarda-se a afirmativa anterior: o Estado é preferencialmente custeado por tributos de caráter contributivo. Junto a essa assertiva, é também necessário que se examinem quais as possibilidades de atuação do Estado para que realize suas funções, com o propósito de estruturar uma sociedade justa.

Já se encontra dito e redito, mesmo em manuais de cursos de graduação, que o Estado pode exercer suas funções mediante atuações diretas, mas também indiretas; é o que faz quando regulamenta e fiscaliza a iniciativa privada, por exemplo. Mesmo quando a iniciativa privada explora atividade econômica de titularidade da sociedade civil, não se a retira do âmbito normativo e fiscalizatório do Estado. O próprio texto da Constituição Federal se encarrega de limitar a iniciativa privada por outros princípios, como dignidade humana, trabalho, preservação ambiental, justa concorrência e função social. Para isso, o Estado pode, não apenas, a) atuar diretamente na área da assistência, previdência, habitação, saúde, educação - e outras tantas atuações necessárias à garantia da dignidade material, o que faz custeado pela riqueza privada que através de tributos é direcionada aos seus cofres, b) como pode regulamentar a iniciativa privada e fiscalizá-la.

Chega-se à seguinte ordem de indagações: quais os limites à transferência da atuação direta estatal para a regulatória, no sentido de o Estado se liberar de atuações diretas à medida que as atribui à iniciativa privada? Pode-se dar um exemplo de quando isso acontece: é função do Estado assegurar a dignidade do trabalhador. No entanto, enquanto estiver ele empregado, o empregador, por normatividade jurídica, é quem se obriga a um salário que o Estado julga o mínimo condizente com a dignidade humana, assim como passa a ser responsabilizado pelo custeio parcial da previdência do empregado ou prestador de serviços.

Ao pensar sobre essa questão, compreende-se que o parâmetro para se delimitar os limites dessa transferência da responsabilidade é o dos meios e não o dos fins. Assim sendo, o debate deve dar-se sobre os condicionamentos necessários para que se exerçam atividades, mas não sobre a imposição de "fins" específicos à iniciativa privada, que teria o propósito de a enquadrar em um modelo pré-concebido do que seria o bom e o valoroso.

Para a fundamentação da afirmação acima, trazem-se algumas considerações: a) a igualdade material se caracteriza pela ausência de hierarquias entre os vários modelos de vida (DWORKIN, 2000, P. 285); b) uma sociedade democrática é uma sociedade que se estrutura sobre uma relação de cooperação entre pessoas livres e iguais, na qual uma não é melhor ou pior do que a outra; c) no convívio espontâneo entre pessoas diferentes e incomensuráveis não é possível a eleição ou adoção de finalidades comuns que devam ser impostas à sociedade (HAYEK, 1976, p. 3); e d) a imposição de fins quebraria a igualdade, por resultar não de uma preferência pública ou coletiva comum, mas das preferências das pessoas que dominam a máquina estatal (HAYEK, 1976, p. 6). Por essa miríade de razões, não se pode impor fins: a 
igualdade demanda que as pessoas sejam igualmente livres para perseguir os seus fins. Mas a regulação de meios é necessária, uma vez que a liberdade absoluta não é possível.

Dito isto, afirma-se que os condicionamentos, ou regulações, ao exercício da atividade privada devem se dar pela perspectiva do meio: o indispensável, necessário e adequado de condicionamentos que se deva impor de maneira que se compatibilize o exercício das liberdades básicas e fundamentais entre si, bem como com os outros interesses que permeiam a Constituição Federal. Não obstante, caso esse mínimo ainda não seja suficiente e ainda se careça da logística pública para se assegurar o que a Constituição tenha configurado como direito, ela deve ser estruturada mediante o custeio preferencial por impostos ou contribuições com causa jurídica na capacidade contributiva.

A Constituição, ao adotar o modelo de Estado Fiscal, está a trabalhar com a logística de que as funções públicas devam ser custeadas mediante uma tributação de caráter contributivo, com esteio na capacidade contributiva, de forma a se manter, conforme o já assinalado: uma justa distribuição de riqueza, que não desequilibre a concorrência e que promova a justa oportunidade para preenchimento de cargos e funções sociais de responsabilidade. Para tanto, o custeio de atividades e benefícios para que se assegure, materialmente, a dignidade humana deve dar-se, repita-se, por tributos com causa na capacidade contributiva.

\subsection{A questão do custeio horizontal da acessibilidade em escolas privadas}

Sob o parâmetro acima assinalado, deve-se também examinar a titularidade da responsabilidade por atividades direcionadas a assegurar a dignidade humana. Trocando em miúdos, a proposta do presente artigo consiste na(s): a) possibilidade de se condicionar a iniciativa privada, de maneira a compatibilizar o seu exercício entre os seus diversos atores, bem como com os demais princípios e interesses da Constituição federal; b) atuações diretas do Estado, a serem custeadas, preferencialmente, por tributos de caráter contributivo.

Deve dar-se preferência à segunda forma de custeio: os condicionamentos resultam no custeio horizontal, no qual os custos dos direitos tendem a ser distribuídos de forma, quantitativamente, igual para todos. Nessa forma de custeio, não é medida a capacidade de cada agente econômico, de maneira que a atribuição dos encargos gera diferentes impactos: grande ônus para uns, o que pode chegar mesmo a inviabilizar a fruição de um serviço ou a aquisição de um produto, não obstante em demasia leve para outros. Com isso, corre-se, por um lado, o risco de que a atribuição de custos tenha efeitos confiscatórios e, de outro, que ela fomente a acumulação perversa de renda e riqueza.

Daí a compreensão de que esse é um parâmetro pelo qual se deve também analisar as questões referentes à inserção social, econômica e política, isto é, o modelo constitucional de atribuição de custos de direitos e funções públicas por entre os cidadãos. Aquilo que supere uma política, imprescindível de meios, ao que ora se denomina de condicionamentos deve ser custeado pelo poder público mediante uma tributação com causa na capacidade contributiva. A solidariedade social se realiza, prioritariamente, pela capacidade contributiva, e não por uma distribuição horizontal de custos que, sem ater-se à riqueza dos agentes, gera o risco do confisco a muitos ao mesmo tempo em que implica privilégio para aquelas poucas pessoas cujo ônus dessa forma de custeio não afeta a situação patrimonial presente.

\section{Conclusão}

O senso educacional no Brasil é tão forte que o constituinte o normatizou como sendo um direito social e um dever do Estado e da família, devendo ser promovida e incentivada com a colaboração da sociedade, visando ao pleno desenvolvimento da pessoa, seu preparo para o exercício da cidadania e sua qualificação para o trabalho. Neste ínterim, a educação ganhou um duplo status, passando a integrar o rol tanto de direito quanto de dever, o que demonstra o elevado interesse do país em promover o acesso ao ensino em todas as suas vertentes (sejam elas elementares, sejam de nível superior). 
Essa perspectiva ganhou nova vida com o surgimento do olhar inclusivo que caracteriza as democracias contemporâneas, nas quais os conflitos não mais se revelam numa estrutura polarizada entre proletariado e dono dos meios de produção. Antes, a busca por reconhecimento de igual dignidade de predicados pessoais, que sejam objeto de discriminação social, trouxe complexidade à questão social, econômica e política ao demandar ações cada vez mais sofisticadas para se estruturar uma sociedade equitativa entre diferentes.

O desafio democrático de se construir uma sociedade equitativa reivindica variadas intervenções e ações estatais, de maneira a se assegurar que as decisões políticas e de mercado resultem de oportunidades equitativas de participação e deliberação. Para tanto, tem-se reconhecido o papel crescente da educação, tanto porque possibilita conhecimentos técnicos necessários à competição por cargos e funções sociais, políticas e econômicas de responsabilidade - como porque propicia os mecanismos para que a pessoa se desenvolva de forma autêntica, mediante reflexão crítica daquilo que realmente lhe importa. Além disso, fomenta a intencionalidade de uma axiologia imanente democrática, caracterizada pelo respeito mútuo, pela reciprocidade e pelo pluralismo; por consequência, propicia um senso de dignidade pessoal e auto-respeito.

Nesse diapasão, a acessibilidade e a inclusão na educação de pessoas com deficiênciafísica e mental se mostram elementar para a construção de uma sociedade "democrática justa", ressalvando-se o que de redundante se encontre nessa expressão. E imbuído desse propósito de "justiça democrática", caracterizada pela cooperação e inclusão mediante a efetivação da igualdade material, o STF analisou a constitucionalidade de lei que atribui às instituições privadas a obrigação de arcar com todos os gastos necessários para recepcionar alunos que tenham qualquer deficiência física, sem que, para tanto, haja repasse de custos aos pais. Para o Min Relator, tal medida se adéqua às diretrizes estabelecidas pela Constituição Federal, segundo as quais o setor privado deve se adequar ao compromisso constitucional e internacional de proteção e ampliação progressiva dos direitos fundamentais e humanos das pessoas com deficiência.

Entretanto, tal abordagem deve ser complementada pela do custo, especificamente pelo modelo constitucional para o custeio de direitos. A atividade de normatização e fiscalização da iniciativa privada deve ser realizada sob o parâmetro de meios, ou condicionamentos, necessários para se compatibilizar o exercício da atividade entre os seus agentes e com os direitos e interesses constitucionais. Isto supere a possibilidade de imposição de condicionamentos, que deve ser suportadoa pelo Estado mediante atividades diretas que sejam custeadas por uma tributação com causa na capacidade contributiva.

Ainda que referido modelo possa aparentar ser, efetivamente, vago conceitualmente, ele serve de norte para se orientar os debates: os princípios constitucionais tributários, dentre os quais os da capacidade contributiva, mais do que restritos a impostos, referem-se a um modelo geral de custeio de direitos reconhecidos constitucionalmente.

\section{Referências}

BRASIL. Constituição (1988). Constituição da República Federativa do Brasil. Brasília: Imprensa Oficial, 1988.

BRASIL. Ministério da Educação. Lei de Diretrizes e Bases da Educação Nacional. LDB 9.394, de 20 de dezembro de 1996. Disponível em: <https://www2.senado.leg.br/bdsf/bitstream/handle/id/70320/65. pdf>. Acesso em: 14 dez. 2016.

BRASIL. Ministério da Educação. Secretaria de Educação Especial. Diretrizes Nacionais para a Educação Especial na Educação Básica. Brasília: MEC/SEESP, 2001.

BRASIL. Ministério da Educação. Secretaria de Educação Especial. Política Nacional de Educação Especial na Perspectiva da Educação Inclusiva. Brasília: MEC/SEESP, 2008.

BRASIL. Ministério da Educação. Secretaria de Educação Especial. Decreto № 6.571, de 17 de setembro de 2008. Disponível em: <http://www.planalto.gov.br/ccivil_03/_ato2007-2010/2008/decreto/ d6571.htm>. Acesso em: 14 dez. 2016. 
BRASIL. A Convenção sobre direitos das pessoas com deficiência comentada. Coordenação de Ana Paula Crosara Resende e Flávia Maria de Paiva Vital. Brasília: Secretaria Especial dos Direitos Humanos, 2008.

BRASIL. Estatuto da Criança e do Adolescente no Brasil. Lei n 8.069, de 13 de julho de 1990. Disponível em: <http://www.planalto.gov.br/ccivil_03/leis//8069.htm>. Acesso em: 14 dez. 2016.

BRASIL. Supremo Tribunal Federal. ADI 5357 MC - Ref / DF - Distrito Federal. Referendo na Medida Cautelar na Ação Direta de Inconstitucionalidade. Relator: Min. Edson Fachin. Julgamento: 09/06/2016. Órgão Julgador: Tribunal Pleno. Disponível em: <http://redir.stf.jus.br/paginadorpub/paginador. jsp?docTP=TP\&docID=12012290 > . Acesso: $14 \mathrm{dez} 2016$.

CURY, Carlos Roberto Jamil. A Constituição de Weimar: um capítulo para a educação. Educação e Sociedade, Campinas, v. 19, n. 63, p. 83-104, ago. 1998.

CURY, Carlos Roberto Jamil. Políticas inclusivas e compensatórias na educação básica. Cadernos de Pesquisa, São Paulo, v. 35, n. 124, p. 11-32, jan./abr. 2005.

CURY, Carlos Roberto Jamil. A educação básica como direito. Cadernos de Pesquisa, São Paulo, v. 38, n. 134, p. 293-303, maio/ago. 2008.

DEMARCHI, Clovis. Autonomia do direito educacional. Disponível em: <http://www2.univali.br/ revistaREDE/rede2/artigos/artigo1.doc>. Acesso em: 24 jun. 2006.

DWORKIN. Uma questão de princípio. Tradução de Luís Carlos Borges. São Paulo: Martins Fontes, 2000.

FREIRE, Paulo. Educação como prática de liberdade: a sociedade brasileira em transição. Rio de Janeiro: Paz e Terra, 2000.

GARCIA, Rosalba Maria Cardoso. Políticas públicas de inclusão: uma análise no campo da educação especial brasileira. Disponível em: <https://repositorio.ufsc.br/handle/123456789/87561>. Acesso em: 12 dez. 2016

GLAT, Rosana; FERNANDES, Edicléa Mascarenhas. Da educação segregada à educação inclusiva: uma breve reflexão sobre os paradigmas educacionais no contexto da educação especial brasileira. Inclusão - Revista da Educação Especial, Brasília, n.1, p. 35-39, out. 2005, MEC/ SEESP. Disponível em: < https://pt-static.z-dn.net/files/df5/ac5f60b62303b5061bfba7c01690e129.pdf>. Acesso em: 14 dez. 2016.

GOES, Ana Carolina Marques de. Educação inclusiva de alunos com deficiência: direito à diversidade. Disponível em: <http://intertemas.toledoprudente.edu.br/revista/index.php/ETIC/article/ viewFile/2281/1862>. Acesso em: 14 dez. 2016.

HAYEK, Friedric A. Law, legislation and liberty: the mirage of social justice. Chicago: The University of Chicago Press, 1976.

ILLOUZ, Eva. O amor nos tempos do capitalismo. Tradução de Vera Ribeiro. Rio de Janeiro: Zahar, 2011.

INNERARITY, Daniel. A política em tempos de indignação. Córdoba: Dom Quixote, 2016.

MANTOAN, Maria Teresa Eglér. Igualdade e diferenças na escola: como andar no fio da navalha. In: MANTOAN, Maria Teresa Eglér; PRIETO, Rosângela Gavioli. Inclusão escolar: pontos e contrapontos. São Paulo: Summus, 2006. p. 15-29.

MENDES, Lucas. Liberdade e bens primários: uma investigação da teoria de John Rawls a partir do liberalismo clássico. 2009. 122 f. Dissertação (Mestrado do Mestrado Interinstitucional em Filosofia) Universidade Federal de Santa Maria, Santa Maria, 2009.

NABAIS, José Casalta. O dever fundamental de pagar impostos. Coimbra: Almedina, 2004.

OFICINA REGIONAL DE EDUCACIÓN DE LA UNESCO PARA AMÉRICA LATINA Y EL CARIBE (OREALC/UNESCO Santiago). El derecho a una educación de calidad para todo em América Latina y 
el Caribe. Revista Electrónica Iberoamericana sobre Calidad, Eficacia y Cambio en Educación, Madrid, v. 5, n. 3, p. 1-21, 2007.

RAWLS, J. A theory of justice. Cambridge: Harvard University Press, 1971.

RAWLS, J. The priority of right and ideas of the good. In: FREEMAM, Samuel (Org.). John Rawls: collect papers. Cambridge: Harvard University Press, 1999. p. 449-472.

RAWLS, J. Justiça como equidade: uma reformulação. São Paulo: Martins Fontes, 2003. (Coleção Justiça e Direito).

RAWLS, J. Justiça e Democracia. Tradução de: Irene A. Patermot. Seleção, apresentação e glossário: Catherine Audrad. São Paulo: Martins Fontes, 2000.

RODRIGUES, Marcella Regina Gruppi. Igualdade: um debate entre Dworkin e Amartya Sem. Disponível em: < http://www.publicadireito.com.br/artigos/?cod=0631ba089fcd29d7>. Acesso em: 14 dez. 2016.

SEN, Amartya K. Desigualdade reexaminada. Rio de Janeiro: Record, 2001.

SILVA, Sidney Reinaldo da. Democracia, estado e educação: uma contraposição entre tendências. Revista Brasileira de Política e Administração da Educação, Porto Alegre, v. 26, n. 1, p. 31-54, jan./ abr., 2010.

SIQUEIRA, Natercia Sampaio. Tributo, mercado e neutralidade no estado democrático de Direito. Rio de Janeiro: Lumen Juris, 2012.

VITA, Álvaro de. Justiça liberal: argumentos liberais contra o neoliberalismo. Rio de Janeiro: Paz e Terra, 1993.

Recebido em: 15/05/2017

Aprovado em: 04/05/2018 